\title{
EXPERIENCES FROM THE PROJECT COURSE IN GEOINFORMATICS
}

\author{
H. Haggrén ${ }^{1}$, P. Ståhle ${ }^{1}$, M. Vaaja ${ }^{1}$, P. Rönnholm ${ }^{1}$, \\ P. Sarkola ${ }^{2}$, M. Rautiainen ${ }^{1}$, M. Nordman ${ }^{1}$, J. Nikander ${ }^{1}$ \\ ${ }^{1}$ Department of Built Environment, Aalto University, P.O. BOX 14100, 00076 AALTO, Finland - (henrik.haggren, pirjo.stahle, \\ matti.t.vaaja, miina.a.rautiainen, maaria.nordman, jussi.nikander)@aalto.fi \\ ${ }^{2}$ GISPO Oy, Kalevankatu 31, 00100 Helsinki, Finland - pekka@ gispo.fi
}

\section{Commission V, WG I}

KEY WORDS: Project-based learning, case learning, self-directive group work, SCRUM, self-reflection, facilitation

\begin{abstract}
:
The aim of this paper is to share our experiences and thoughts about a project course in geoinformatics. The course has been organised annually since 2017 . We hope that this article provides ideas about when new project-based courses are designed or existing ones are renewed. We wanted to increase students' motivation by providing assignments from companies or other organisations as well as cooperation with them. Working with real clients makes the project work much more interesting than projects without a real-life connection. We provide topics from various fields of geoinformatics, such as geoinformation technology, geodesy, photogrammetry, laser scanning and remote sensing. The students worked in small groups that were supported by an advisor and a facilitator. The advisor helps with substance and the facilitator assists with reflection and improving working process, i.e. not only to complete the task but also to learn about capabilities for project work, self-directive teamwork and learning to learn (meta learning). To sum up, during the course students increase their knowledge and expertise on geoinformatics, learn skills for client-centered project work and learn how to support their learning through self- and peer-reflection. In other words, the course aims to develop skills that are useful throughout the students' forthcoming careers.
\end{abstract}

\section{INTRODUCTION}

In 2016, a new Master's programme in geoinformatics was introduced at the School of Engineering at Aalto University, Finland. As a result of programme development (Rönnholm and Haggrén, 2016), a new project course was established. The course was offered for the first time in 2017 , and was designed to serve all our sub-fields of geoinformatics, since the renovation merged three former master's programmes into one. Currently, we operate in the following fields: geoinformation technology, geodesy, photogrammetry, laser scanning and remote sensing. In our previous master's programmes, we had significant experience of various types of project courses. However, this time we managed to add more dimensions for effective learning than before.

The main issue with project courses is how to create genuine motivation for students, since motivation is a root reason for effective learning (e.g. Chang and Chang, 2012; Tohidi and Jabbari, 2012). Several theories about learning motivations exist, such as intrinsic and extrinsic motivation theory, selfdetermination theory, the ARCS model, social cognitive theory and expectancy theory (Gopalan et al., 2017) that inspired us in our course design. For example, providing invigorating and relevant topics increases intrinsic motivation, which we achieved by providing real-life cases and real client cooperation. Also, structured and facilitated group work creates an environment that supports learning, effective group dynamics and a positive atmosphere. Furthermore, advising and facilitation provide a boost to motivation by arousing students' attention towards the learning process, and increasing their understanding of it.

The aim of this paper is to share our experiences and thoughts about how a project course in geoinformatics can be effectively implemented. We hope that this article provides ideas to other universities when new project courses are being designed or existing ones are renewed. The course has been delivered three times, and this article incorporates the lessons learnt from each of them. The main structure of the course remained largely the same in all three instances. However, small adjustments between the years were made based on student and teacher feedback.

\section{THE MAIN CHARACTERISTICS AND THE TIMETABLE OF THE PROJECT COURSE}

Our 10 ECTS project course is part of the elective courses of major studies in the Master's programme in geoinformatics. The general structure of the programme is shown in Figure 1. The number of participants in this project course has varied between 10 and 17. For most students, this is the last of the major courses they take. In addition, the course has also been popular with exchange students. The project course lasts for two teaching periods which, in practice, means about three months of effective working time.

Running the project course requires one organiser, at least one facilitator, and as many advisors and clients as there are groups. The size of the groups has varied between two and five members; however, the optimum number is three or four. A simplified timetable of the course is illustrated in Figure 2.

In addition to the final product and a report produced for a client, the outcomes of the course include a final presentation with a poster, an individual learning diary, and each group's logbook about their working process. If a project topic includes programming tasks, source codes or even software also form part of the output. 


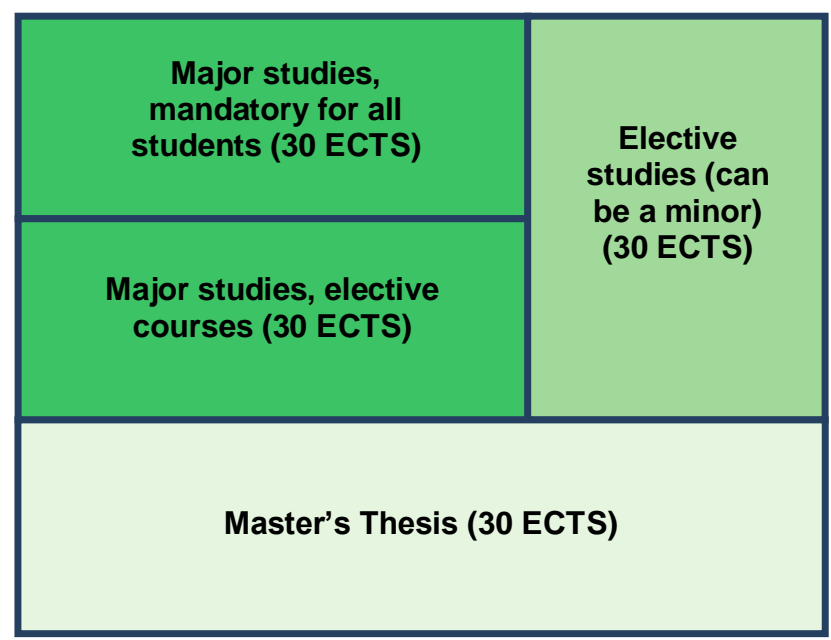

Figure 1. Programme structure. The project course is one of the elective major studies courses in the Master's degree programme in geoinformatics. Students can select 30 ECTS from a pool of several courses.

\section{Preparation of the course}

\section{Opening event}

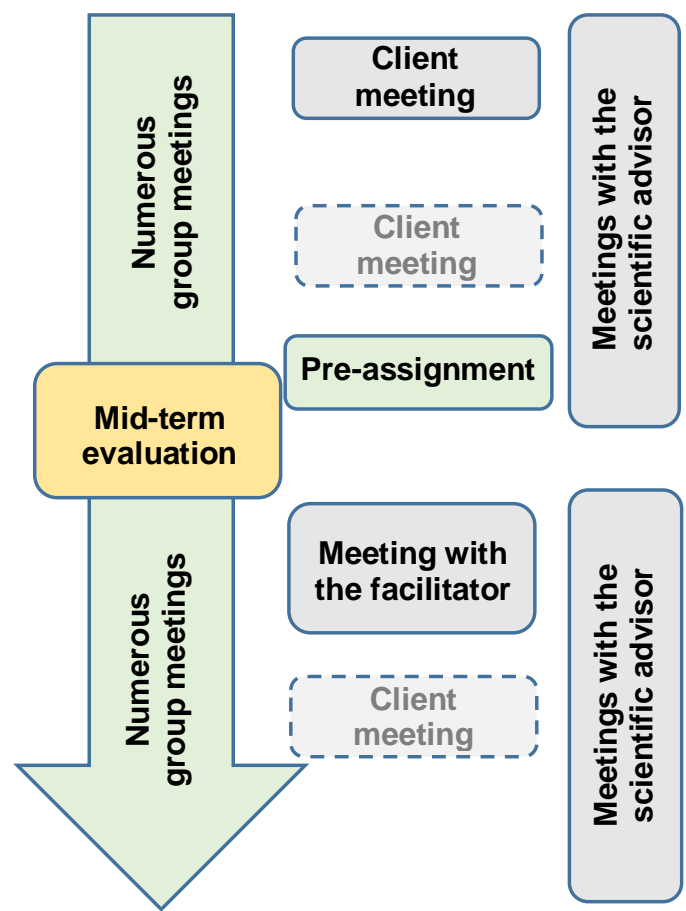

Final seminar

\section{Deliveries to client}

\section{Evaluation meeting}

Figure 2. The structure of the project course. The number of meetings with the client and the scientific advisor can vary, depending on the demand.

\section{AIMS AND THEORETICAL BASES OF OUR PROJECT COURSE}

With our project course, our first aim is to increase students' knowledge and expertise of geoinformatics. Project work topics vary, and therefore there are no precise geoinformatics learning goals as part of the course. Instead, each project group will deepen their understanding related to the topic of their project, and our goal is for each project group to produce concrete and applicable results for their client. However, the learning goals of the course extend beyond geoinformatics. We also want our students to comprehensively learn various dimensions of clientcentred project work, such as using project management tools, and to improve their skills for directing their own group work.

Although the central parts of the course focus on project work, we emphasise how students can learn skills to reflect on and evaluate their behaviour in order to support their learning. We believe that such skills enable improving personal performance throughout a person's whole working career.

The tools and structures that we have utilised in the course design are based on appropriate theories. In addition to the motivational elements discussed earlier, one of the key foundations of the course is self-directedness. In practice, this means that students are given general goals and basic structures, but they work in selfdirected groups and specify their goals, working methods and ways to proceed by themselves and/or together with their client. Since Knowles (1975) right up to the present day, selfdirectedness has been a thoroughly studied topic in educational sciences (e.g. Dynan et al., 2008; Merriam, 2001; Pintrich, 2004; Raemdonc, 2013; Ståhle, 1998). The intensified interest in selfdirection or self-organisation has been brought about by the effects of globalisation and communication technology. Through these developments, organisations have become increasingly difficult to manage by controlling from the top down. Management today is more about navigation than control, and work is more closely akin to surfing than the mechanistic implementation of plans (Ståhle and Åberg, 2015).

Another important element of the course is self-reflection. Learning diaries support students to make sense of their experiences and reflect on their ways of learning. Self-reflection is also deeply studied in research literature, and it is widely acknowledged as an antecedent for transformative learning and meta learning, i.e. learning to learn (Mezirow, 1991; Sinnot, 2011). Self-directedness and self-reflection improve students' learning capabilities, but also their creativity (Poutanen and Ståhle, 2014).

In the following chapters, we describe how the principles of selfdirectedness and self-reflection have been operationalised in our project course, and what kinds of supportive structures we have created for them.

\section{IMPLEMENTATION OF THE PROJECT COURSE}

\subsection{Preparation of the course}

Searching for clients and topics should be done well before the course begins. In this course, we provide topics related to geoinformation technology, geodesy, photogrammetry, laser scanning and remote sensing. Searching for suitable topics requires many discussions with possible clients. A good topic is interesting but not too strictly defined. This enables students to widely apply their knowledge and skills. Furthermore, the 
associated problem should be possible to solve within the given time and workload frames. In addition, it is important to find a client who is willing to interact with students and to assist the group during the course.

Finding suitable topics and clients requires contacts and insight into subjects from the staff. However, this is also a great opportunity to maintain existing contacts and to create new ones between companies, other organisations and the university. When the course was initiated in 2017 , the opportunity to provide topics for the course was promoted through the Finnish Location Information Cluster (https://www.flic.fi) in many companies. In practice, the background of participating clients has varied a lot. We have had companies of varying sizes, research centres, cities and municipalities as clients.

The number of topics is also important. We aim to get three or four students in one group. This, together with the total number of students enrolled, defines how many groups we are able to establish. Optimally, we would like to provide only the minimum number of topics. In practice, we need one or two topics more than will be used on the course. We have asked clients to write a brief description of their topic, as this allows students to explore topics before they choose.

\subsection{Initialising projects in an opening event}

The project course starts with an opening event. The event begins with orientation to the course. In this phase, we highlight the goals and objectives of the course, and explain practical issues, such as working practicalities, the meaning of advice and facilitation, the requirements of keeping a logbook and a learning diary, evaluation criteria, and the structure of the course.

After the orientation, we continue with the project topics. In this context, we emphasise to students that they need to make an agreement regarding immaterial property rights with the client, if they expect that their work will lead to something profitable. Each topic is introduced and the names of the client's contact persons and scientific advisors are revealed.

\subsection{Project working phase supported by advice and facilitation}

Since external clients are involved, each group arranges a meeting with company representatives. Usually, the group's scientific advisor participates in this meeting. This face-to-face meeting is essential for students to find out about and discuss the clients' expectations. Usually, this meeting does not provide strict guidance or a road map on how to proceed, but it is something that must be formulated and concretised by the group itself. In addition, it has been recognised that it is important to have this meeting as early as possible so that project work can get off to a good start.

The group defines their goals and establishes a project management system. We have used different methods regarding how to approach this part. In the beginning, we provided links to several project management tools, from which the group selected one. However, recently we have asked students to apply SCRUM (Sutherland and Schwaber, 2013) in order to reduce the workload from this tool selection phase.

After a group has managed to establish its working practicalities, they perform the first brainstorming session and decide the first working path. The group presents their ideas to the scientific advisor. The role of a scientific advisor is to support the students to select a sensible working approach for meeting the client's expectations. In addition, the advisor can give suggestions on how to organise project management. However, their role is only to support the group, not to make decisions for it.

A mid-term evaluation is carried out, in order to give students the opportunity to present the current state of their project. For this stage, we have experimented with two different approaches. The first one included only the presentation of working processes and the second one included both working processes and the current state of the project. Currently, we prefer both the contents of the project and the working methods to be presented. Since one outcome of the project course is a poster, at this mid-point, we have also arranged a lecture about making posters.

Before the mid-term session, students have performed a small pre-assignment that is applied to group self-evaluation. During the meeting, groups benchmark their assessments. We have also reserved time for open questions and comments. The preassignment contains the following nine questions with their supporting points:

1. How effectively did you apply the SCRUM method?

- $\quad$ To what extent did you learn the method?

- How did the method support your project?

2. Progress according to plans

- Status quo: what has been achieved so far?

- Current outcomes versus the objectives, definitions and designs that were set at the beginning.

3. Time and process management

- Framework, methods and practices that you have used

4. Activity and deliverables of the group members

- Roles and responsibilities: objectives, reality, concerns

- (In)equality of the workload

5. General atmosphere and energy level

- Variations, roadblocks, energisers

6. Effectiveness of the meetings

- How could effectiveness be improved?

7. Balance of conflict resolution and avoidance

- What kinds of conflicts have you experienced?

- Are there any issues/contradictory opinions that should be discussed?

8. Balance of goal orientation and creative reflection

- Is there enough creativity in the work?

- In what way could you be more creative?

9. Lessons learnt

- What are the key learnings so far?

- Have you learnt less/more than you hoped for?

All the students have scored the group's performance on a scale of 1-5 for each of the items. During the session, following a discussion, they jointly agree the groups' overall score, and decide how to improve their performance from then on.

After the mid-term check, we have arranged a facilitation meeting. The purpose of this meeting is different from meetings with a scientific advisor. The facilitator does not comment on the project topic, but aims to support group dynamics and working processes. This helps the students to handle issues that have an influence on the motivation and efficiency of the group. Support can include helping all the group members to express their 
thoughts and feelings about the joint working process, supporting them to bring out ideas on how to improve their work, and becoming aware of the possible bottlenecks of the project. Even if the role of a facilitator is not to give immediate answers to existing problems, sometimes direct advice can also be given. However, only around $20 \%$ of a meeting is taken up by the facilitator's questions and comments; the rest is down to the students. It is usually advantageous to raise discussions about problematic themes that a group did not manage, notice, or want to deal with by itself - even if no solution can be found. It is an advantage for the facilitator to not be an expert of geoinformatics, since it helps keep the focus on the work process rather than the substance. A facilitation meeting is expected to last for about 1.5 hours. However, students are free to contact the facilitator whenever they feel they need support.

In practice, individual facilitation meetings can vary significantly, based on the situation and the problems that the groups have. However, generally the basic structure is the same. At first, the facilitator emphasises the aims of a facilitation meeting in order to ensure that students understand the nature of the meeting. The group members define the three most acute topics that they want to discuss themselves. Next, there is a discussion about selected topics utilising the following four aspects:

1. Currents status. Students describe what has happened, how they feel about the current situation, and how a problem appears.

2. Core and name of a problem. The facilitator asks students to define the core of a problem, and to give it a name. Students make suggestions and together a concise name and description is given to the problem.

3. Solving a problem. Students discuss and make suggestions about possible solution scenarios. The facilitator keeps track of suggestions, and repeats them now and then with additional questions aiming to find out more ideas, and underlines the key suggestions. Finally, the facilitator asks students how they plan to solve the problem.

4. Generalisation. The facilitator turns the discussion to what kind of general working principles have been revealed. The idea is to identify processes and methods that may prevent similar problems from occurring in future projects.

Before the final seminar, there can be several meetings with the scientific advisor and client, and naturally a lot of work to produce the desired results. In the final seminar, all outcomes are presented and clients are invited to follow the presentations. Each group begins by giving a short presentation (ca. 10 minutes) about the working processes that they applied to their work, with key insights and learning. In this presentation, students are asked to answer three main questions:

1. What did you aim to achieve at the beginning of the project, and what did you ultimately achieve? How would you assess your achievements?

2. What was (were) the turning point(s) in the working process? What was the key reason for the turn?

3. Based on this experience, what are the key learning points related to project management?

After that, the group gives a poster presentation about the project results (ca. 10 minutes, Figure 3). After the presentation, there is time for the audience to ask questions about the poster (ca. 15 minutes). After each presentation, there is 15 minutes for a self- and peer-feedback session, i.e. all groups (presenting group included) are asked to evaluate current presentation and the poster within their groups. After the groups are ready, each group, starting with the presenting group, shares their thoughts on the pros and cons of the outcomes and the presentation. The process is repeated with each group. At the end of the final seminar we ask all the students to individually evaluate the whole course.

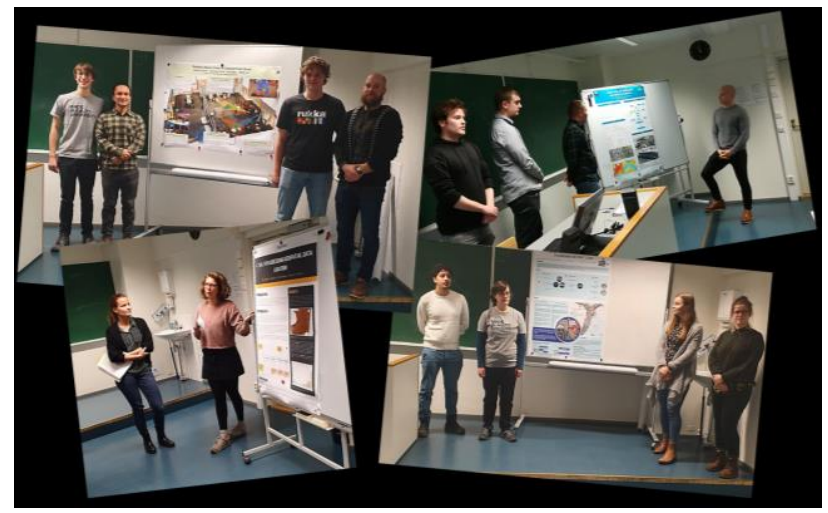

Figure 3. Examples of posters in a final seminar.

\subsection{Learning diary as a tool for self-reflection}

Throughout the whole course, students write individual learning diaries. Writing a learning diary gives students the opportunity to reflect on their individual process of learning, and thus improve their metacognitive skills (Clipa et al., 2012). A good learning diary reflects the student's own development and learning process, and thus, it often becomes a 'dialogue' between a student and the new information and experiences achieved during the course. It is also an excellent tool for developing one's ability to reason in general. We consider this part especially important, because it assists students to become more aware of the dimensions and factors that have a major impact on performance and results, but are hard to recognise. These can be power issues, communication modes or lack of self-confidence. Such awareness increases so-called meta-learning capabilities, i.e. learning to learn. As a result, students may also make new findings of important success factors in client-centred projects.

Learning diaries may be implemented in many ways, but for our learning objectives, we decided to ask students to place special emphasis on the following main questions:

- How did the project go? How did you feel about it?

- What went well? Why?

- What was not so good? Why?

- How could this have been done differently?

- What should you change or work on for next time?

- What prevented you from doing as well as you could?

- What have you learnt, or improved?

- Describe the way you tackle things - your strategies

- Things you found out about yourself

\subsection{Evaluation}

The evaluation of project work can be difficult. In our case, we decided to use three categories that were graded: project outcome $(50 \%)$, working process $(25 \%)$ and individual learning diary $(25 \%)$. Each category is graded using the Finnish system, which is from 0 (fail) to 5 (excellent). The final course grade is 
combined from these categories. For the purposes of evaluation, all advisors and facilitator(s) have a meeting in which a collective grading of each category is given. This is advantageous to harmonising grading criteria.

The project outcome category includes the results of the project and the quality of the poster. We also ask clients to give their opinion on the project outcomes from their perspective. In principle, we give the same project outcome grade to everyone in a group, unless there is clear evidence that someone has not participated equally in the project. Typically, such special cases are difficult to evaluate, and need a case-wise judgement based on all evidence, but one criterion can be the estimated work hours of a student compared with the expected 270 working hours, which corresponds to 10 ECTS.

The main means to evaluate working process criteria are facilitators' and advisors' observations and the group's logbook. However, in some cases individual diaries also give valuable information on how well the group managed in their working processes. Mainly, this category deals with the project management skills of the group. The grade for this category is usually the same for the whole group.

The learning diaries reveal how deeply a student has managed to analyse their own and the group's behaviour. We have instructed students to focus on analysing their behaviour and not to simply list what they have done. The highest scores are given to those diaries that are reflective and analytical, and the lowest score to diaries that only report what has happened.

\section{FEEDBACK ON THE COURSE}

We have collected feedback after each course since 2017. In addition to official feedback, we get a lot of feedback during the mid-term evaluation and the final seminar, as well as in meetings with the scientific advisor and the facilitator. Overall, the students have graded our project course as "very good" (ca. 4 out of 5). Most of the students have been pleased with their study effort on the course. In the first year, 2017, students estimated that the workload of the course significantly exceeded the requirements of 10 ECTS. However, since then we have encouraged students to monitor and arrange their workload within acceptable limits. As a result, in 2019 students estimated the workload to be exactly as expected. Students have strongly agreed that in the future they will benefit from the things they learnt on the course (4.7 out of 5).

Overall, students have been most satisfied with the interesting topics, the effectiveness of self-directed work, the presence of real clients, working life-based experiences, project management methodologies, learning diaries for self-reflection, meetings with the scientific advisor, meetings with the facilitator, mid-termcheck evaluations, working in groups, and the freedom to implement the projects.

Most of complaints have been related to communication. We have continuously tried to improve our communication in order to provide clear and timely instructions. However, this work continues. In addition, the freedom to implement the project and the demand that students have to find out themselves what the client's real needs are and how to proceed with the project causes distress to some students. Obviously, this divides students' opinions, since the same things also appear as positives. Notably, when we left out the presentation on the status of groups' projects in the mid-term evaluation, this was remarked on in the feedback.

\section{DISCUSSION}

Three implementations have given us experiences about how the project course currently functions. The participation of exchange students provides more varied backgrounds for groups, which we have found a richness. As the course is at the end of the Master's degree studies, students have the opportunity to utilise all the previously-learnt skills they have gained. However, because topics come from external clients, students need to learn more in order to achieve good results. The presence of companies seems to give a boost to general motivation, and most of the students are willing to put a lot effort into this course. In addition, companies have found the results to be valuable.

In practice, students have three months' time to complete a project. As the size of the project course is 10 ETCS, it is expected that groups manage to accomplish some significant results. Still, the given time is short and the course, typically, becomes progressively more intensive - even if most of the course is self-directed. In many cases, students are excited about the projects and occasionally, advisors have to remind students to focus their work in such a way that the expected workload is not exceeded. However, there is always a risk in group work that some students do not do the same amount of work as others. Such cases are usually revealed in learning diaries and facilitation meetings.

The feedback on the project course has been encouraging. Generally, students have valued that they have gained practical experiences of cooperation with companies, as well as from project work methods. The poster session and presentations advance students' presentation and communication skills. In addition, students have been very interested in other groups' results.

Facilitation has been one of the major things that has enhanced the project course to a higher level. Many students have expressed that the facilitation meeting was one of the turning points in the course that actually changed the working methods of groups. However, the mid-term event and meetings with advisors have also been significant in terms of enabling project work to proceed smoothly.

It seems to be advantageous to highlight that students can, and should, learn about working processes in order to improve forthcoming projects. Too easily, students' focus is only on how to complete a given task. Instruction to complete a learning diary emphasises that self-reflection is utterly important, because in that way a student can realise their behaviour and group dynamics in project work. This enables improvement of one's behaviour. In addition, peer evaluation combined with self-reflection has also proved to be efficient. An example of this can be found from the evaluation of presentations and posters at the final seminar. Usually, both types of evaluations seem to improve during the final seminar when students learn from each other how to evaluate outcomes.

The evaluation meeting allows staff to discuss grading scales. This is a good method for harmonising grading. This meeting usually leads to more general discussions among staff about state-of-the-art methods and acute needs of different sub-fields of geoinformatics, namely geoinformation technology, geodesy, photogrammetry, laser scanning and remote sensing, in our case. It is positive how different sub-topics and working cultures can be mixed together. 
Company representatives have typically been very satisfied with our project course. For example, in 2019, all clients had a representative at the final seminar. The clients' general feeling has been that communicating with students has not been too timeconsuming, considering the benefits. However, it is important to make an agreement regarding immaterial property rights if it seems the project will lead to a significant contribution. This project course is usually the last one before starting the master's thesis, and therefore it provides a good foundation and preparation for choosing a theme. In addition, students make valuable connections with companies - and vice versa. In the future, we consider if the clients' opinion should have more influence in our grading system.

\section{CONCLUSION}

We have described our implementation of a project course in geoinformatics. The key elements of our project course are reallife topics, presence of external clients, project management tools, scientific advice, facilitation, applicable results, presentations, poster sessions and self-reflection. Facilitation provides students with advanced working skills by revealing how to analyse one's own behaviour, and how that can improve further projects.

We have been particularly satisfied with this course, and the related feedback has been encouraging. We have noticed that students are able to increase their knowledge and expertise of geoinformatics during the course. The average grade of the participants is 4.04 with the standard deviation of 0.54 . In addition, they learn valuable skills for client-centred project work. The emphasis on self-reflection in diaries enables students to realise how they can support their learning and analyse their behaviour in a group. We believe that such skills are useful to them throughout their forthcoming careers.

Developing and running this project course has been interesting. It is rewarding to see how students find the course interesting and beneficial. Clients have been very satisfied with cooperation, which strengthens their connections to the university. We believe that we have managed to create a functional concept that is worthwhile continuing.

\section{ACKNOWLEDGEMENTS}

The authors would like to thank Aalto University A!WorkLifePilots, which supported the establishment of the course in 2017.

\section{REFERENCES}

Chang, I.-Y., Chang, W.-Y., 2012. The effect of student learning motivation on learning satisfaction. The International Journal of Organizational Innovation, 4(3), 281-305.

Clipa, O., Ignat, A.-A. and Stanciu, M., 2012. Learning diary as a tool for metacognitive strategies development. Procedia Social and Behavioral Sciences, 33, 905-909.

Dynan, L., Cate, T., Rhee, K., 2008. The impact of learning structure on students' readiness for self-directed learning. Journal of Education for Business, 84(2), 96-100.
Gopalan, V., Bakar, J., Zulkifli, A., Alwi, A., Mat, R., 2017. A Review of the Motivation Theories in Learning. AIP Conf. Proc., 1891, 020043-1-020043-7.

Knowles, M., 1975. Self-directed learning. New York: Association Press, 135 pages.

Merriam, S., 2001. Andragogy and self-directed learning: "Pillars of adult learning theory." New Directions for Adult and Continuing Education, 89, 3-13.

Mezirow, J., 1991. Transformative dimensions of adult learning (Jossey-Bass Higher and Adult Education Series). San Francisco, CA: Jossey-Bass, 247 pages.

Pintrich, P., 2004. A conceptual framework for assessing motivation and self-regulated learning in college students. Educational Psychology Review, 16(4), 385-407.

Poutanen, P. K., Ståhle, P., 2014. Creativity in short-term selfdirected groups: An analysis using a complexity-based framework. International Journal of Complexity in Leadership and Management, 2(4), 259-277.

Raemdonck, I. Meurant, C. Balasse, J. Jacot, A., Frenay, M., 2013. Exploring the concept of "self-directedness in learning". Theoretical approaches and measurement in adult education literature. In: Gijbels, D. Donche, V. Richardson, J. and Vermunt, J. Learning patterns in higher education: Dimensions and research perspectives. New York, US: Routledge, 78-101.

Rönnholm. P., Haggrén, H. 2016. Development and Implementation of a New Master's Programme in Geoinformatics at Aalto University, Finland. The Photogrammetric Journal of Finland, 25(1), 1-19.

Sinnott, J. D., 2011. Constructing the self in the face of aging and death: Complex thought and learning. In C. Hoare (Ed.), The Oxford Handbook of Reciprocal Adult Development and Learning, Oxford Library of Psychology, 2nd ed., New York, NY: Oxford University Press, 248-264.

Ståhle, P., 1998. Supporting a system's capacity for self-renewal. Department of Teacher Education. University of Helsinki. Research Report 190, 381 pages.

Ståhle, P., Åberg, L., 2015. Organizations in a Non-Linear, Unpredictable World. Business and Management Studies, 1(1), 6-12.

Sutherland, J., Schwaber, K., 2013. The scrum guide. The definitive guide to scrum: The rules of the game. Scrum.org., 268 pages.

Tohidi, H., Jabbari, M., 2012. The effects of Motivation in Education. Procedia - Social and Behavioral Sciences, 31, 820824.

Tuckman, B. 1965. Development sequence in small groups. Psychological Bulletin, 63, 384-399. 